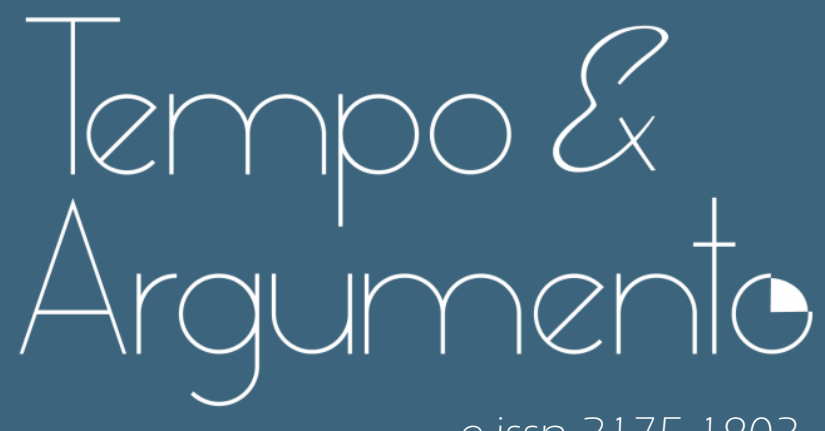

e-issn 2175-1803

Memória e reparação no Ensino Superior: uma análise das Comissões da Verdade Universitárias em São Paulo

- Luana Hanaê Gabriel Homma

Doutoranda em Ciências Humanas e Sociais na Universidade Federal do ABC (UFABC). Santo André, SP - BRASIL lattes.cnpq.br/0914370701019972

luana.homma@ufabc.edu.br

(D) orcid.org/0000-0003-1533-2406

- Maria Gabriela Silva Martins da Cunha Marinho

Doutora em História Social pela Universidade de São Paulo (USP).

Professora da Universidade Federal do ABC (UFABC).

Santo André, SP - BRASIL

lattes.cnpq.br/8368768304963502

gabriela.marinho@ufabc.edu.br

(D) orcid.org/0000-0002-5698-0437

Para citar este artigo:

HOMMA, Luana Hanaê Gabriel; MARINHO, Maria Gabriela S. M. C. Memória e reparação no Ensino Superior: uma análise das Comissões da Verdade Universitárias em São Paulo. Tempo e Argumento, Florianópolis, v. 13, n. 32, e0202, jan./abr. 2021

dof http://dx.doi.org/10.5965/2175180313322021 e0202

Recebido: 05/06/2020

Aprovado: 10/10/2020 


\title{
Memória e reparação no Ensino Superior: uma análise das Comissões da Verdade Universitárias em São Paulo
}

\begin{abstract}
Resumo
O artigo analisa, inicialmente, a instalação e a dinâmica de atuação de Comissões da Verdade Universitárias criadas em diferentes universidades brasileiras a partir de 2012. Contudo, elegeram-se como principais objetos de análise as instituições públicas e privadas do estado de São Paulo. Para tanto, toma como base empírica os relatórios das comissões publicados a partir dos quais procura identificar características e condições de implantação, aderência da comunidade universitária e a correlação de forças favoráveis e contrárias à sua instalação. Atenção especial foi conferida às recomendações formuladas pelas Comissões. A análise documental ocorre de forma situada levando em consideração a conjuntura das Comissões Nacional e Estadual, inseridas no arco temporal de 2012 a 2018. Tal demarcação considerou 2012 como ano de partida, quando afinal se instituíram as primeiras Comissões Universitárias e, 2018, por ter sido o ano de encerramento dos trabalhos da Comissão Universitária da Universidade de São Paulo (USP), a última do estado.
\end{abstract}

Palavras-chave: Memória coletiva. Ditadura Militar - Brasil. Universidade.

\section{Memory and reparation in Higher Education: an analysis of Universities' Truth Commissions in São Paulo}

\begin{abstract}
The article initially analyzes the installation and performance dynamics of University Truth Commissions created in different Brazilian universities since 2012. However, public and private institutions in the state of São Paulo were chosen as the main object of analysis. For this purpose, it takes as an empirical basis the published reports from which it seeks to identify characteristics and conditions of implementation, adherence of the university community and the correlation of favorable and opposite forces to its installation. Special attention was given to the recommendations made by the Commissions. The documentary analysis is situated in a context in which the juncture of the National and State Commissions, inserted in the time frame from 2012 to 2018, is taken into account. Such demarcation considered 2012 as the starting year, when the first University Commissions were finally established. And 2018 for being the closing year for the work of the University Commission of the University of São Paulo (USP), the last in the state.
\end{abstract}

Keywords: Collective memory. Military Dictatorship - Brazil. University. 


\section{Introdução}

A ampla bibliografia sobre o golpe civil-militar de 1964 tem apontado o período como de cerceamento de direitos civis e políticos dos cidadãos brasileiros, incluindo infrações aos direitos humanos com prisões, torturas, censura e assassinatos. Há um razoável consenso sobre o declínio do período mais sombrio da ditadura cujo auge teria ocorrido entre 1968 e 1973, assinalandose a partir de meados da década de 1970 um processo de abertura "lento e gradual", resultado de pressões sociais, do esgotamento do modelo econômico e dos embates e disputas entre os grupos militares no poder. A promulgação da Lei de Anistia ${ }^{1}$ em 1979, por sua vez, tem sido assinalada como um dos pontos de inflexão no tenso processo de abertura política do país, sendo considerada, também, como resultado consistente da mobilização social que a precedeu por meio da formação de vários comitês locais.

Desse modo, a luta pela anistia no Brasil configurou-se como reivindicação por um perdão amplo, geral e irrestrito, voltado para presos políticos e exilados que combateram a ditadura (ABRÃO; TORELLY, 2010). No entanto, a Lei de Anistia aprovada ainda no período militar excluía os acusados de participar de luta armada, mas assegurava o perdão para agentes do Estado, inclusive para responsáveis por práticas violentas, entre as quais figuram sequestros, assassinatos e tortura (BRAGATTO; PAULA, 2011; OLIVEIRA; MARINHO, 2013). Apenas com a redemocratização vivenciada pelo país ao longo da década de 1980, que viria a culminar com a chamada Constituição Cidadã promulgada em 1988 e com a realização de eleições presidenciais em 1989, ampliou-se o alcance da Anistia.

Contudo, a ambiguidade das transições negociadas pode ser entrevista nos detalhes e nas contradições. Por exemplo, o marco legal assegurado pela Constituição Federal de 1988 consignou em suas disposições transitórias que a anistia deveria ser concedida àqueles que a partir de 18 de setembro de 1946, até a promulgação da nova Carta Magna, "foram atingidos, em decorrência de motivação exclusivamente política, por atos de exceção, institucionais ou complementares [...]" (BRASIL, 1988, art. 8 ADCT).

${ }^{1}$ Lei no 6.683, de 28 de agosto de 1979. 
Tal dispositivo evidencia a rejeição à anistia bilateral, que de fato prevaleceu e incluiu não apenas os perseguidos, mas também os perseguidores (ABRÃO; TORELLY, 2010). Por outro lado, somente a partir dessa acomodação, presos políticos foram libertados e os exilados puderam retornar para o país (OLIVEIRA; MARINHO, 2013). Segundo Genro e Abrão (2010), tais arranjos não foram exclusivos da transição brasileira. Acomodações semelhantes foram negociadas em outros países da América Latina que passaram por regimes autoritários, impedindo uma efetiva ruptura. Portanto, para esses autores, a democracia na América Latina expandiu-se mais como "forma" do que como "substância". As contradições decorrentes desse processo foram retomadas no período subsequente, quando emergiram demandas que se consubstanciaram nos debates formulados em torno da chamada "Justiça de Transição".

O termo Justiça de Transição foi cunhado em 1991 por Ruti Teitel em referência "aos processos de transformação política e jurídica nos contextos de transições para as 'novas democracias' na América Latina e na Europa do Leste” (SANTOS, 2010, p. 129). Genro e Abrão (2010, p. 23) consideram que não se trata de "uma forma especial de justiça, mas uma justiça de caráter restaurativo, na qual as sociedades transformam a si mesmas depois de um período de violação generalizada dos direitos humanos".

Juan Méndes, ex-presidente da Comissão Interamericana de Direitos Humanos, aponta quatro principais áreas de atuação da justiça transicional. São elas: 1) A justiça, por meio da responsabilização penal dos violadores de Direitos Humanos; 2) O direito à verdade e à informação, ou seja, à memória, por meio de Comissões da Verdade, Justiça ou Reconciliação; 3) A reparação por meio de indenizações ou de medidas simbólicas; 4) O impedimento de que funcionários do Estado que cometeram tais violações exerçam funções públicas (apud SANTOS, 2010).

A partir da década de 2000, particularmente no período dos governos de centro-esquerda, algumas ações do Estado brasileiro pautaram-se por tais princípios. Nessa direção, um dos eventos mais relevantes foi o Projeto Memórias Reveladas. Lançado em 2009 pela Casa Civil da Presidência da República, a iniciativa criou um centro de referência para acolher fisicamente os documentos 
relativos ao período da ditadura, acoplado por sua vez a um centro de referência virtual. Outra ação relevante foi assegurar a ampliação do trabalho realizado pela Comissão Especial sobre Mortos e Desaparecidos Políticos criada em 1995 a fim de localizar os restos mortais e o reconhecimento por parte do Estado dos assassinatos e dos desaparecidos pela ditadura civil-militar (TORELLY, 2010).

Contudo, um ponto decisivo na experiência da Justiça Restaurativa no país foi a criação da Comissão Nacional da Verdade por meio da Lei 12.528, de 18 de novembro de 2011, visando apurar violações aos Direitos Humanos no período entre 1946 e 1988. A partir da Comissão Nacional, foram criadas Comissões Estaduais, Municipais e Setoriais, incluindo as Comissões Universitárias. Nas universidades, as comissões foram criadas para investigar e evidenciar violações de direitos por parte de membros do governo nas instituições de ensino superior.

Em 2012 instituiu-se a primeira delas, a Comissão Anísio Teixeira de Memória e Verdade da Universidade Federal de Brasília, instalada no dia 10 de agosto. No ano seguinte, 2013, foram instaladas, em sua maioria, as Comissões da Verdade das instituições paulistas, exceto na Universidade Estadual Júlio de Mesquita Filho, instituída em 2014. A dinâmica de constituição e funcionamento é o objeto central desse artigo, como poderá ser acompanhado ao longo do texto. Para tanto, o artigo foi organizado em quatro seções, além da introdução. A primeira parte apresenta o debate teórico acerca das políticas de memória nos contextos de transição com ênfase nas Políticas de Memória e Comissões da Verdade. A segunda dedica-se ao levantamento e contexto de criação das Comissões da Verdade Universitárias no Brasil.

A terceira seção concentra-se especificamente na análise das Comissões instituídas em seis instituições paulistas: Universidade de São Paulo (USP), Universidade de Campinas (UNICAMP), Universidade Estadual Júlio de Mesquita Filho (UNESP), Pontifícia Universidade Católica de São Paulo (PUC-SP), Universidade Federal de São Paulo (UNIFESP), Fundação Escola de Sociologia e Política de São Paulo (FESPSP). Por fim, as considerações finais apresentam algumas das conclusões decorrentes da pesquisa e análise. 


\section{Políticas de memória e Comissões da Verdade}

As Comissões da Verdade em suas diferentes instâncias - nacional, estaduais, municipais ou temáticas - tornaram-se importantes instrumentos de memória e subsídio para políticas de reparação. No caso brasileiro, permitiram ultrapassar os limites da perspectiva oficial cristalizada pelas narrativas de membros do regime civil-militar, assegurando a emergência do ponto de vista daqueles que atuaram na oposição e enfrentamento da ruptura institucional, tornando-se em decorrência objeto da violência e do arbítrio do Estado de Exceção.

Nessa direção, diversos trabalhos têm evidenciado a relevância da memória, como apontado por Bragatto e Paula (2011, p. 130), para quem "sem memória não há história, sem memória não há justiça”. As autoras defendem que "[n]o meio do caminho entre a violência e a justiça encontra-se a memória, como condição de neutralização da primeira e de possibilidade para a segunda." (BRAGATTO; PAULA, 2011, p. 131).

Em abordagem complementar, Soraia Ansara (2012) identifica a naturalização e a normalização do período da ditadura como expressão da colonialidade do poder. Destaca que dessa forma se constrói uma memória oficial que mantém as relações de poder daqueles que arbitrariamente o usurparam, agregando desse modo significados adicionais à categoria "colonialidade do poder", termo cunhado por Aníbal Quijano (2005) para caracterizar o sistema de dominação perpetrado por europeus nas Américas. Trata-se, segundo Quijano (2005), de um sistema que insere e classifica indivíduos em relações de hierarquização geográfica, e sobretudo racial, construindo assimetrias de poder tratadas como "naturais".

No caso brasileiro, a naturalização se traduz, por exemplo, em homenagens a agentes da repressão cujos nomes batizam ruas, praças, escolas (TORELLY, 2010). Ainda assim, por se tratar de uma disputa que permanece viva no interior das sociedades, "a memória manifesta-se como forma de resistência e luta política fortalecendo a participação e ação política de movimentos sociais" (ANSARA, 2012, p. 299). Por outro lado, um aspecto dessa disputa, lembram Oliveira e Marinho (2013), comparece em obras de memorialistas com papéis 
distintos, opondo as narrativas de agentes da repressão aos relatos de vítimas da ditadura. Na perspectiva de militares, por exemplo, recorre-se à defesa da ordem e do progresso como justificativa para o que consideram "eventuais excessos".

Desse modo, a dimensão da memória como instrumento de resistência política não permite o esquecimento. Mobiliza o resgate da violência e do sofrimento para evidenciar a injustiça e o arbítrio que seguem no presente, tornando o passado menos abstrato e distante, para desnaturalizar perspectivas e convicções (BRAGATTO; PAULA, 2011). Nessa direção, Bragatto e Paula (2011) assinalam a condição da memória como direito, dado que "esquecer" permite a continuação e a repetição da violência, reproduzindo e perpetuando a injustiça. Portanto, a memória e as Comissões da Verdade se tornam decisivas na interdição às violações e como instrumento de justiça e reparação às vítimas de violações (GENRO; ABRÃO, 2010).

O caráter dual da memória e a compreensão de seus usos podem reafirmar o discurso oficial por meio inclusive de instituições centrais na vida social, como escolas e mídia. Por outro lado, é igualmente decisiva na luta política de enfrentamento ao arbítrio (ANSARA, 2012) e no contraponto de versões. Tratase, portanto, não de revisar a história, mas de permitir que sejam ouvidas narrativas sufocadas pela repressão (SILVA FILHO, 2010).

Contudo, como assinala Molinero (2010), deve-se considerar que a memória não substitui a pesquisa e a análise histórica, posto que a primeira busca "recordar, honrar, denunciar ou condenar", enquanto a segunda pretende compreender e explicar processos e períodos. Nessa direção, Ansara (2012) pontua a diferença entre políticas de memória e políticas de preservação do patrimônio histórico ou com a institucionalização da memória, dado que "a história é uma representação do passado e uma operação intelectual que rompe os vínculos coletivos da memória, na medida em que se cristaliza na escrita da história oficial” (ANSARA, 2012, p. 304).

Por outro lado, a memória assegura o vínculo entre passado e presente, mantendo-se a possibilidade tanto da lembrança quanto do esquecimento. Portanto, uma das formas de manutenção de poder é a que promove a 
destruição da memória dos vencidos. Para subjugá-la e impedir que esta questione o domínio dos vencedores, se instala um confronto de memórias e uma disputa de sentidos (ANSARA, 2012). Para Molinero (2010), os conflitos em torno da memória da ditadura se dão durante a constituição da democracia, na busca pela compreensão do que aconteceu com aqueles que desapareceram ou foram mortos, cumprindo desse modo uma função pedagógica e de reparação.

Na disputa de sentidos estão contrapostas políticas de memória e políticas de esquecimento, sendo que estas buscam a fabricação de consensos, visando recuperar a harmonia nacional e apagar o passado conflituoso. Como pontua Silva Filho (2010), os processos de anistia atuam também como apagamento da própria memória, o que se verificou, por exemplo, em relação à Lei de Anistia de 1979. Tal apagamento pode ser operado por elementos simbólicos como a manipulação política e ideológica dos meios de comunicação, de instituições de ensino, pela ação dos esportes, difusão do medo, por indicadores econômicos, estímulo ao patriotismo, ou por meios materiais, como a destruição de arquivos, fato comum na experiência das Comissões Universitárias. Por fim, o apagamento da memória é sedimentado também pela impunidade, seja pela falta de reconhecimento ou de punição dos crimes cometidos nos períodos de arbítrio (ANSARA, 2012).

No caso, brasileiro, os debates em torno do autoritarismo se mantiveram ao longo da redemocratização na década de 1980 e foram aguçados nos anos 2000. Em 2007, por exemplo, a Secretaria Especial dos Direitos Humanos e o Ministério da Justiça manifestaram publicamente a necessidade de investigar o período para que o país pudesse aprofundar a democracia. Em decorrência, emergiu nesse contexto o tema da revisão da Lei da Anistia em relação aos crimes cometidos pelo Estado, como tortura, assassinato e desaparecimento forçado (SANTOS, 2010). Porém, outros órgãos de Estado, como o Ministério da Defesa e a Advocacia Geral da União, se opuseram sob o argumento de que a Lei de Anistia assegurava que o passado deveria ser esquecido pelo bem da estabilidade política (SANTOS, 2010).

Um marco relevante na política de memória promovida pelo Estado brasileiro correu em 2010, com o lançamento do 3ㅇ Plano Nacional de Direitos 
Memória e reparação no Ensino Superior: uma análise das Comissões da Verdade Universitárias em São Paulo

Luana Hanaê Gabriel Homma, Maria Gabriela Silva Martins da Cunha Marinho

Humanos (PNDH-3), que revisou e aprofundou os planos anteriores de 1996 e 2002. Em 2010, entre os seis eixos do Plano, destacou-se o eixo destinando ao Direito à Memória e à Verdade, consignando a questão enquanto direito humano. No contexto, portanto, de valorização e reconhecimento do direito à memória, emergiu a proposição de instalação de uma Comissão Nacional da Verdade (SANTOS, 2010). Tratou-se de um ponto de inflexão em relação aos períodos anteriores, como detalhado a seguir.

Durante seus dois governos (1994-2002), Fernando Henrique Cardoso se opôs à criação da Comissão da Verdade e ampliou o período de sigilo para documentos militares, orientação que permaneceu ao longo do governo Lula, quando se propôs inclusive projeto de lei pela manutenção da figura do sigilo eterno (SANTOS, 2010). Em âmbito internacional, no entanto, a decisão em 2001 da Corte Interamericana de Direitos Humanos avançou em relação ao tema no caso Barrios Altos versus Peru², ao decidir que proposições de autoanistia não são leis de fato (SANTOS, 2010). Desde então, a justiça brasileira passou a conceder decisões favoráveis a peticionários enquadrados nessa modalidade e em 2003 foi criada Comissão Interministerial para obter informações sobre os corpos dos desaparecidos da Guerrilha do Araguaia ${ }^{3}$ (SANTOS, 2010).

\footnotetext{
2 O caso Barrios Alto vs Peru, julgado na Corte Interamericana de Direitos Humanos, diz respeito a questões de autoanistia e impunidade. No ano de 1991, seis indivíduos armados ingressaram em uma festa na cidade de Lima e executaram quinze pessoas, ferindo outras quatro gravemente. Soube-se posteriormente que os assassinos eram parte do Grupo Colina, um "esquadrão de eliminação" antissubversivo do exército peruano, e a ação teria sido feita em represália ao grupo comunista Sendero Luminoso. Após tentativas de investigação, foi sancionada em 1995 uma lei de anistia (Lei no 26.479) excluindo a responsabilidade de militares, policiais e civis que tivessem cometido violações de direitos humanos entre os anos de 1980 e 1995. O caso foi para a Comissão Interamericana de Direitos Humanos, onde foi julgado como incompatível com a convenção da qual o Peru é Estado Parte, e encaminhado posteriormente para a Corte, que decidiu, entre outros, que o Estado peruano deveria atuar no sentido de investigar e punir os responsáveis, adotando medidas de reparação para as vítimas e os seus familiares (CORTE, 2010).

Durante o período da ditadura militar, grupos contrários ao regime se organizaram de diversas formas, inclusive em partidos políticos (em sua maioria na ilegalidade). Alguns dos integrantes do PCdoB (Partido Comunista do Brasil), se organizaram na chamada Guerrilha do Araguaia, no Pará, visando mobilizar a população do campo. Foram diversas as ações do Estado na região, que já contava com conflitos entre a população e as forças do Estado mesmo antes da chegada deste grupo. Os militares passaram a se focar no combate à guerrilha, neutralizando suas ações pelo uso de diversas táticas, incluindo as mais violentas (até mesmo com os cidadãos não envolvidos na militância). Com isso, a maior parte dos guerrilheiros é até hoje considerada desaparecida, e, mesmo em relação aos que foram identificados como mortos nos documentos, não se tem muita informação acerca das condições da morte e de localizações dos corpos sepultados (BRASIL, 2014).
} 
Porém, a Comissão Nacional da Verdade (CNV) seria instalada cerca de uma década depois. Criada com a Lei no 12.528, de 18 de novembro de 2011, teve seu relatório publicado em 2014, e foi antecedida pela instalação da Secretaria de Direitos Humanos da Presidência da República no âmbito da qual se criou o projeto Memorial Pessoas Imprescindíveis, visando a construção de memoriais demarcadores dos arbítrios cometidos pela ditadura. Em 2009, um desses memoriais foi instituído no Teatro da Pontifícia Universidade Católica de São Paulo (TUCA/PUC-SP), destinado a rememorar cinco estudantes da instituição mortos durante o regime militar (BRASIL, 2014). No mesmo ano, iniciativas semelhantes foram criadas na Universidade de São Paulo ${ }^{4}$ e na Universidade Federal de Alagoas ${ }^{5}$ (BRASIL, 2014).

Uma vez instalada, a Comissão Nacional da Verdade se voltou para casos de graves violações de direitos humanos, orientando "seus trabalhos para o exame e esclarecimento de detenções ilegais e arbitrárias, torturas, mortes, desaparecimentos forçados e ocultação de cadáveres" (BRASIL, 2014, p. 38). A atuação da Comissão Nacional estimulou a instalação das comissões estaduais, municipais e temáticas. Em São Paulo, a iniciativa estadual resultou na Resolução no 879, de 10 de fevereiro de 2012, que no âmbito da Assembleia Legislativa criou a Comissão da Verdade do Estado de São Paulo "Rubens Fonseca”, a primeira dessa esfera no país.

Composta por dez deputados estaduais, cinco efetivos e dez substitutos, e assessorada por diversos profissionais, a Comissão buscava em colaboração com a CNV efetivar o direito à memória e à verdade em relação aos eventos ocorridos durante a ditadura no Brasil. O trabalho foi realizado a partir de testemunhos, informações e documentos encaminhados voluntariamente, requisitados ao poder público ou através de cooperação com outras instituições. Atuou por meio de audiências públicas, quando foram colhidos depoimentos de convidados ou depoentes voluntários.

\footnotetext{
${ }^{4}$ Foram lembrados os estudantes de Medicina Antônio Carlos Nogueira Cabral e Gelson Reicher. 5 o memorial erguido nesta instituição foi em homenagem aos alagoanos mortos na ditadura: Odijas Carvalho de Souza, José Dalmo Guimarães, José Gomes Teixeira, Luiz Almeida Araújo, Gastone Lúcia de Carvalho Beltrão, Manoel Lisboa de Moura, Túlio Roberto Cardoso, Jayme Amorim de Miranda e Manoel Fiel Filho.
} 
As experiências de outros países foram igualmente relevantes como parâmetro e referência de atuação. O Relatório Final da Comissão Nacional (BRASIL, 2014) indica mais de 30 experiências internacionais em todos os continentes, embora por vezes a denominação tenha sido diferente. Por exemplo, a experiência de Uganda comparece como Comissão de Inquérito sobre o Desaparecimento de Pessoas (1974) e na Bolívia (1982) denominada por Comissão Nacional de Investigação de Desaparecidos (BRASIL, 2014).

No Cone Sul, a primeira iniciativa nomeada como Comissão da Verdade foi promovida pela Argentina que instituiu, em 1983, a Comissão Nacional sobre o Desaparecimento de Pessoas (CONADEP). O Chile criou sua Comissão da Verdade e Reconciliação em 1989. Catorze anos depois, o país aprofundou sua política em busca de memória e reparação, criando em 2003 a Comissão Nacional sobre Prisão Política e Tortura (BRASIL, 2014).

No caso brasileiro, a Comissão Nacional da Verdade contou também com a colaboração de órgãos internacionais voltados para os direitos humanos, além de dados obtidos junto às comissões locais, estaduais, municipais ou temáticas. No âmbito internacional, recebeu informações de órgãos da Argentina e Uruguai com atividades periciais e exumação dos restos mortais de João Goulart, além do intercâmbio de informações de graves violações de direitos humanos nos três países. (BRASIL, 2014).

\section{As Comissões da Verdade Universitárias}

Espaço privilegiado de produção, reflexão profunda, crítica e debate aberto, as Universidades são, em todo mundo, foco de repressão de governos autoritários, se tornando também e por decorrência disso, espaço de oposição política e resistência ao arbítrio. No Brasil, a instalação de Comissões da Verdade Universitárias buscou evidenciar como a ditadura agiu diretamente sobre essas instituições com o objetivo de calar, reprimir e interditar a produção crítica. Ao mesmo tempo, pretendeu também evidenciar ações de resistência ou colaboração provenientes da comunidade universitária. 
A repressão ao meio universitário e a tentativa de controle ideológico são frequentes em outras partes do mundo submetidas a ditaduras. Na Espanha, por exemplo, desde seu início o regime franquista perseguiu o corpo docente de instituições universitárias assegurando, por outro lado, que apoiadores permanecessem em sua composição (OLIVER, 2008). O movimento estudantil também é objeto da repressão porque se coloca frequentemente como força de resistência contra os governos ditatoriais no Brasil assim como na Espanha franquista (OLIVER, 2008) ou na ditadura na Argentina (SEIA, 2016). Outro foco de oposição no interior das universidades são os movimentos sindicais, além de docentes que individualmente se projetaram como críticos incômodos. Contudo, casos de cooperação com o regime também foram frequentes, como registraram as Comissões da Verdade Universitárias (MOTTA, 2008).

As Comissões Universitárias colocaram em relevo a robustez do sistema de informações montado pelo regime militar no interior das instituições, por meio das Assessorias Especiais de Segurança e Informações (AESIs) que se espalhavam também por autarquias, empresas públicas e fundações. Tais órgãos coletavam, sistematizavam e repassavam informações para as Divisões de Segurança e Informação que por sua vez alimentavam o Sistema Nacional de Informação (SNI) (FAGUNDES, 2018; MOTTA, 2008). Muito frequentemente, os documentos produzidos pelas AESIs universitárias foram destruídos ou desapareceram. Porém, por meio das Comissões foram encontrados vários documentos, incluindo registros bastante completos.

Criadas a partir de 1971 em 35 universidades, em sua maioria instituições federais, as Assessorias de Segurança não eram obrigatórias nas instituições estaduais como a Universidade de São Paulo (USP) ou a Universidade Estadual de Londrina (UEL) que ainda assim foram monitoradas por meio desses órgãos (MÜLLER; FAGUNDES, 2014; MOTTA, 2008). Vinculadas diretamente aos reitores, além de coletar, organizar e fornecer informações, funcionaram também como instrumento de pressão e controle sobre as reitorias e a comunidade universitária (MOTTA, 2008). As Comissões Universitárias apuraram ações nesse sentido, desde interferência na contratação de professores até o controle das manifestações estudantis, alcançando também atividades de pesquisa, eventos 
científicos e cerimônias acadêmicas (MOTTA, 2008). Em 1979, as Assessorias de Seguranças foram extintas pelo MEC, porém algumas subsistiram até 1986 quando seis remanescentes finalmente cessaram as atividades. (MÜLLER; FAGUNDES, 2014).

Desse modo, enquanto a Comissão Nacional se ocupou especialmente das violações aos direitos humanos, as Comissões Universitárias atuaram em sua esfera, evidenciando danos ao corpo docente, discente e de servidores, além de intervenções diretas no funcionamento destas instituições. Geograficamente, as Comissões Universitárias se estabeleceram por todo país, registrando-se pelo menos uma delas em cada macrorregião.

Instaladas a partir de 2012, a Tabela 1, a seguir indica sua distribuição por macrorregião, por instituição e registra o documento legal de criação.

Tabela 1: Comissões da Verdade Universitárias no Brasil

\begin{tabular}{|c|c|c|c|c|c|}
\hline Nome & Região & UF & IES & Âmbito & Criação \\
\hline $\begin{array}{c}\text { Comissão Anísio Teixeira de } \\
\text { Memória e Verdade da } \\
\text { Universidade Federal de Brasília }\end{array}$ & $\begin{array}{l}\text { Centro- } \\
\text { Oeste }\end{array}$ & DF & UnB & Federal & $\begin{array}{l}\text { Resolução da Reitoria no } \\
\text { 85/2012, de } 10 \text { de agosto } \\
\text { de } 2012\end{array}$ \\
\hline Comissão da Verdade - UFRN & Nordeste & RN & UFRN & Federal & $\begin{array}{l}\text { Portaria no } 1.809 / 12-R \text {, de } \\
31 \text { de outubro de } 2012\end{array}$ \\
\hline Comissão da Verdade - UFPR & Sul & PR & UFPR & Federal & $\begin{array}{l}\text { Portaria no 2440, de } 09 \\
\text { de novembro de } 2012\end{array}$ \\
\hline Comissão da Verdade - UFFS & Sul & RS & UFFS & Federal & $\begin{array}{c}\text { Portaria no } \\
\text { 1129/GR/UFFS/2012, de } \\
28 \text { de novembro de } 2012\end{array}$ \\
\hline Comissão da Verdade - USP & Sudeste & $\mathrm{SP}$ & USP & Estadual & $\begin{array}{l}\text { Portaria GR no } 6172 \text {, de } \\
07 \text { de maio de } 2013\end{array}$ \\
\hline $\begin{array}{c}\text { Comissão da Verdade da PUC-SP } \\
\text { Reitora Nadir Gouvêa Kfouri - } \\
\text { CVPUC }\end{array}$ & Sudeste & $\mathrm{SP}$ & PUC-SP & Privada & $\begin{array}{l}\text { Ato de Criação no } 02 \text { de } \\
10 \text { de maio de } 2013\end{array}$ \\
\hline $\begin{array}{c}\text { Comissão da Memória e Verdade } \\
\text { - UFRJ }\end{array}$ & Sudeste & RJ & UFRJ & Federal & $\begin{array}{l}\text { Portaria no 4966, de } 02 \\
\quad \text { de maio de } 2013\end{array}$ \\
\hline Comissão da Verdade - UFES & Sudeste & ES & UFES & Federal & $\begin{array}{l}\text { Portaria no } 478 \text {, de } 27 \text { de } \\
\quad \text { fevereiro de } 2013\end{array}$ \\
\hline $\begin{array}{l}\text { Comissão da Verdade "Marcos } \\
\text { Lindenberg" da Universidade } \\
\text { Federal de São Paulo (UNIFESP) }\end{array}$ & Sudeste & $\mathrm{SP}$ & Unifesp & Federal & $\begin{array}{l}\text { Resolução no } 88 \text {, de } 12 \\
\text { de junho de } 2013\end{array}$ \\
\hline $\begin{array}{l}\text { Comissão da Verdade e Memória: } \\
\text { Pela Construção do Nunca Mais }\end{array}$ & Sudeste & $\mathrm{SP}$ & FESPSP & Privada & $\begin{array}{c}\text { Ato de Instalação em } 19 \\
\text { de junho de } 2013\end{array}$ \\
\hline
\end{tabular}




\begin{tabular}{|c|c|c|c|c|c|}
\hline $\begin{array}{l}\text { Comissão da Verdade das } \\
\text { Universidades do Estado do } \\
\text { Ceará }\end{array}$ & Nordeste & CE & $\begin{array}{l}\text { UFC e } \\
\text { UECE }\end{array}$ & $\begin{array}{l}\text { Federal } \\
\mathrm{e} \\
\text { Estadual }\end{array}$ & $\begin{array}{l}\text { Portaria Conjunta UECE e } \\
\text { UFC, de no } 01 \text { de } 9 \text { de } \\
\text { julho de } 2013\end{array}$ \\
\hline $\begin{array}{c}\text { Comissão "César Moraes Leite" } \\
\text { de Memória e Verdade e o } \\
\text { Conselho Superior } \\
\text { (Consun/UFPA) }\end{array}$ & Norte & PA & UFPA & Federal & $\begin{array}{l}\text { Resolução do Consun no } \\
\text { 721, de } 20 \text { de setembro } \\
\text { de } 2013\end{array}$ \\
\hline $\begin{array}{c}\text { Comissão da Verdade e Memória } \\
\text { Octávio lanni }\end{array}$ & Sudeste & SP & Unicamp & Estadual & $\begin{array}{l}\text { Portaria GR 111/2013, de } \\
20 \text { de setembro de } 2013\end{array}$ \\
\hline $\begin{array}{c}\text { Comissão de Memória e Verdade } \\
\text { da Universidade Federal de } \\
\text { Campina Grande }\end{array}$ & Nordeste & PB & UFCG & Federal & $\begin{array}{l}\text { Resolução N.o 12/2013, de } \\
18 \text { de outubro de } 2013\end{array}$ \\
\hline $\begin{array}{l}\text { Comissão Milton Santos de } \\
\text { Memória e Verdade- UFBA }\end{array}$ & Nordeste & BA & UFBA & Federal & $\begin{array}{l}\text { Resolução } \mathrm{n} \text { - 10/ } \\
25 \text { de outubro c }\end{array}$ \\
\hline Comissão da Verdade - UNESP & Sudeste & SP & Unesp & Estadual & $\begin{array}{l}\text { Portaria no } 88, \text { de } 24 \text { de } \\
\quad \text { fevereiro de } 2014\end{array}$ \\
\hline $\begin{array}{c}\text { Comissão Memória e Verdade - } \\
\text { UFSC }\end{array}$ & Sul & SC & UFSC & Federal & $\begin{array}{l}\text { Resolução Normativa no } \\
\text { 48/Cun/2014, de } 16 \text { de } \\
\text { dezembro de } 2014\end{array}$ \\
\hline $\begin{array}{l}\text { Comissão Paulo Devanier Lauda } \\
\text { de Verdade e Memória - UFSM }\end{array}$ & Sul & RS & UFSM & Federal & $\begin{array}{l}\text { Portaria n. } 75.620 \text {, de } 15 \\
\text { de junho de } 2015\end{array}$ \\
\hline Comissão da Verdade - UEL & Sul & PR & UEL & Estadual & $\begin{array}{l}\text { Portaria no } 7632 \text {, de } 22 \\
\text { de dezembro de } 2015\end{array}$ \\
\hline
\end{tabular}

Fonte: Elaboração das Autoras, 2020.

Um dado relevante no processo foi a articulação, em 2014, de dezenove Comissões Universitárias que buscaram atuar em conjunto por meio da Rede Nacional de Comissões da Verdade Universitárias (ALMEIDA, 2017; MÜLLER; FAGUNDES, 2014). A partir da Rede, algumas recomendações foram encaminhadas para a Comissão Nacional, que dedicou espaços para questões temáticas em seu Relatório Final. Além do tema da repressão nas Universidades, o Relatório abriu espaço para registrar violações de direitos humanos entre operários, camponeses, povos indígenas e o meio militar (ALMEIDA, 2017).

\section{As Comissões da Verdade Universitárias do Estado de São Paulo}

Como indicado anteriormente, a análise refere-se a seis instituições de ensino superior do estado de São Paulo que instalaram Comissões da Verdade, sendo quatro públicas e duas privadas, conforme aponta a tabela a seguir. 
Tabela 2: Comissões Universitárias do Estado de São Paulo

\begin{tabular}{|c|c|c|c|}
\hline Instituição & Sigla & Nome da Comissão & Pública/Privada \\
\hline Universidade de São Paulo & USP & $\begin{array}{c}\text { Comissão da Verdade da } \\
\text { Universidade de São Paulo }\end{array}$ & Pública \\
\hline $\begin{array}{c}\text { Pontifícia Universidade } \\
\text { Católica de São Paulo }\end{array}$ & PUC-SP & $\begin{array}{c}\text { Comissão da Verdade Reitora } \\
\text { Nadir Gouvêa Kfouri }\end{array}$ & Privada \\
\hline $\begin{array}{c}\text { Universidade Federal de São } \\
\text { Paulo }\end{array}$ & Unifesp & $\begin{array}{c}\text { Comissão da Verdade "Marcos } \\
\text { Lindenberg" }\end{array}$ & Pública \\
\hline $\begin{array}{c}\text { Fundação Escola de } \\
\text { Sociologia e Política de São } \\
\text { Paulo }\end{array}$ & FESPSP & $\begin{array}{c}\text { Comissão da Verdade e } \\
\text { Memória: pela construção do } \\
\text { Nunca Mais }\end{array}$ & Pública \\
\hline $\begin{array}{c}\text { Universidade Estadual de } \\
\text { Campinas }\end{array}$ & Unicamp & $\begin{array}{c}\text { Comissão da Verdade e } \\
\text { Memória Octávio lanni }\end{array}$ & Pública \\
\hline Universidade Estadual Paulista & Unesp & $\begin{array}{c}\text { Comissão da Verdade da } \\
\text { Unesp }\end{array}$ & \\
\hline
\end{tabular}

Fonte: Elaboração das Autoras, 2020.

Três dos relatórios finais produzidos pelas Comissões estão disponíveis para consulta pública na internet. Dentre os documentos das Comissões aqui analisadas não se encontram públicos o texto da Comissão da Verdade e Memória: pela construção do Nunca Mais, da Fundação Escola de Sociologia e Política (2014), que foi obtido por correio eletrônico, e o da Comissão da Verdade "Marcos Lindenberg”, da Unifesp, uma vez que, por ora, encontra-se disponível um informe acerca do Relatório Final (UNIVERSIDADE FEDERAL DE SÃO PAULO, 2017), que já contém alguns dos textos que o comporão, e as recomendações dadas pela Comissão6.

O relatório da Comissão da Verdade da UNESP foi solicitado por telefone e correio eletrônico, tendo sido encaminhado apenas um relatório parcial. Por não conter recomendações, o relatório parcial não foi incluído nesta seção. Em boletim da Associação dos Docentes da Unesp (Adunesp) de 26 de março de 2015, pontuou-se a vontade desta Comissão da Verdade de, assim como outras Comissões pelo Brasil, prorrogar seus trabalhos por dois anos. Segundo o Boletim, o Gabinete da Reitoria se negou a realizar audiências e, por informações verbais veiculadas por membro da assessoria da Reitoria, a Comissão foi informada de que tal prorrogação seria negada porque, segundo este, "Precisamos focar no futuro".

\footnotetext{
${ }^{6}$ Disponível em https://www.unifesp.br/images/DCl/Recomendacoes_CONSU_CVML.
} 


\section{Breve contextualização}

Entre maio e setembro de 2013, cinco instituições universitárias de São Paulo criaram suas Comissões da Verdade. Apenas uma se instalou em 2014, mesmo ano de criação da Rede Nacional de Comissões Universitárias. No estado, a primeira foi instalada na Universidade de São Paulo por ato da Reitoria (Portaria GR 6172, de 07 de maio de 2013). O Relatório Final (UNIVERSIDADE DE SÃO PAULO, 2018) foi publicado em 2018, é composto por onze volumes, assim organizados:

- Volume 0: contém apresentação dos volumes seguintes seguido das Recomendações.

- Volume 1: Dedicado inteiramente ao levantamento e análise da atuação da Assessoria Especial de Segurança e Informação.

- Volume 2: Sistematiza informações sobre Mandados de Segurança.

- Volume 3: Dedicado ao levantamento de Mortos e Desaparecidos.

- Volume 4 a 8: Tratam especificamente da repressão nas Faculdades de Medicina (FM-USP), Direito (FD-USP), Arquitetura e Urbanismo (FAU-USP), Filosofia, Letras e Ciências Humanas (FFLCH-USP), Escola de Comunicações e Artes (ECA-USP).

- Volume 9: Reúne Depoimentos de ex-estudantes.

- Volume 10: Discute as Fontes Documentais utilizadas na elaboração do Relatório.

Poucos dias depois, em 10 de maio, a Pontifícia Universidade Católica de São Paulo publicou o Ato de Criação (no 02, de 10 de maio de 2013) que deu origem aos trabalhos que se estenderam até 2017. A comissão homenageia a exreitora Nadir Gouvêa Kfouri, dirigente da instituição no período da ditadura. Oficialmente, a iniciativa foi denominada Comissão da Verdade Nadir Gouvêa Kfouri.

O Relatório Final (COMISSÃO DA VERDADE DA PUC-SP, 2017) está disponível no formato virtual como website com índice em abas que remete para as páginas específicas do Relatório. Composto por dez abas/páginas, o índice remete para os seguintes itens: Apresentação, Metodologia, Mortos e Desaparecidos, Relação Igreja-Universidade, Movimento Estudantil, Comunidade Acadêmica, Lutas pela Anistia, o Teatro da Universidade Católica de São Paulo (TUCA), Recomendações. Por fim, a relação de Integrantes e Contatos da Comissão da Verdade. 
A terceira Comissão foi instalada em junho de 2013 na Universidade Federal de São Paulo (UNIFESP), sob a denominação de Comissão da Verdade Marcos Lindenberg, regulamentada pela Resolução no 88, de 12 de junho de 2013. A denominação é uma homenagem da Comissão ao reitor Marcos Lindenberg, deposto pela ditadura em 1964. Em 2016, publicou o informe sobre o Relatório Final (UNIVERSIDADE FEDERAL DE SÃO PAULO, 2016), indicando as recomendações em documento separado ${ }^{7}$. O informe é composto de textos que integram o Relatório Final, biografias, depoimentos e sumário do Relatório Final, ainda não publicado.

Igualmente, em junho de 2013, a Fundação Escola de Sociologia e Política de São Paulo (FESPSP) instituiu a Comissão da Verdade e Memória: Pela Construção do Nunca Mais. Em agosto do ano seguinte, elaborou o Relatório Final (COMISSÃO DA VERDADE DA FUNDAÇÃO ESCOLA DE SOCIOLOGIA E POLÍTICA DE SÃO PAULO, 2014) que não foi tornado público, mas é composto pela Introdução e a segunda seção com o levantamento dos seguintes temas: Convênios, Censores, Casos Individuais, Organizações Anticomunistas e Desligamento de professores, finalizado pelas Recomendações.

A Comissão da Universidade de Campinas (UNICAMP) foi a última instalada no ano de 2013, regulamentada na instituição pela Portaria GR 111/2013 de 20 de setembro e homenageia Octavio Ianni. O Relatório final (ARAÚJO, et al., 2015) foi publicado em 2015, contendo Introdução e quatro capítulos nos quais constam a justificativa de Caio Navarro de Toledo, depoimentos, cronologias e as recomendações. No ano seguinte, em fevereiro de 2014, a Universidade Estadual Paulista Júlio de Mesquita Filho, emitiu a Portaria UNESP no 88, criando sua Comissão. Os trabalhos foram finalizados em agosto do mesmo ano e a Comissão elaborou um relatório parcial, enviado para a Comissão Nacional da Verdade, sem recomendações.

A análise dos Relatórios Finais e Parciais das Comissões Universitárias revela a estreita relação que estabeleceram com suas congêneres, no caso, a Estadual e a Nacional. 
As informações coletadas e sistematizadas relativas às violações de direitos humanos nas instituições de ensino superior subsidiaram o Relatório Final da Comissão Nacional da Verdade (CNV), compondo principalmente o Volume II, dedicado aos textos temáticos.

A partir de 2014, as Comissões Universitárias articularam a formação da Rede Nacional de Comissões Universitárias, que redigiu as recomendações em relação às universidades e forneceu subsídios para a CNV. Por outro lado, é igualmente notória a inspiração que as Comissões Nacional e Comissão Estadual exerceram nas recomendações dos relatórios finais produzidos nas universidades. As referências variam de citações nominais, explicitando que foram o principal parâmetro para a elaboração das recomendações específicas, até indicações mais discretas em que a inspiração fica implícita, embora se encontrem passagens ipsis litteris?.

\section{Recomendações e Rememorações}

Homenagens como ato político

A análise das recomendações que integram os Relatórios Finais revela a demanda por reparação política e simbólica que emerge das homenagens e menções registradas pelas Comissões Universitárias. No documento ${ }^{9}$ apresentado pela Unifesp, por exemplo, há recomendações específicas, relacionadas à dinâmica e ao ambiente universitário, mas ganham vulto e relevo também aquelas que, direcionadas para a sociedade, fortalecem os vínculos extramuros. Ao desenvolver os trabalhos em parceria com a Comissão da Verdade da Assembleia Legislativa do Estado de São Paulo (CV/Alesp) e com a Comissão de Familiares de Mortos e Desaparecidos Políticos, a Comissão Universitária voltou-se para as investigações das ossadas no cemitério de Perus. Elemento de alto significado emocional e político, a identificação das ossadas na

\footnotetext{
${ }^{8}$ Este é o caso do Relatório da Comissão da Verdade da PUC-SP, que indica os títulos das 29 recomendações da CNV.

${ }^{9}$ Disponível em https://www.unifesp.br/images/DCl/Recomendacoes_CONSU_CVML.
} 
Vala de Perus ${ }^{10}$ recebeu atenção também da Comissão da Verdade da USP, que registra em suas recomendações o auxílio a esse procedimento.

As recomendações específicas são direcionadas para o Centro de Formação e de Estudos de Arqueologia e Antropologia Forense (CAAF/Unifesp), entre as quais se aponta a necessidade de políticas públicas para organização da documentação dos cemitérios públicos, além da manutenção do próprio Centro, e da parceria com a CV/Alesp. Assinala, ainda, a urgência na continuidade dos trabalhos com a Vala de Perus e na melhoria da estrutura física, em especial os laboratórios. Ressalta a necessidade de apresentação e entrega para as famílias das análises de identificação dos dados coletados pelo Banco do DNA. Por fim, indica a urgência de liberação pelos órgãos policiais das fichas datiloscópicas dos desaparecidos políticos que visam a identificação das ossadas de "desconhecidos" ou "indigentes" que se encontram em Perus.

Outro aspecto das atividades das Comissões refere-se à atribuição de homenagens. Ponto relevante das políticas de memória, as homenagens foram destacadas em todas as Comissões Universitárias analisadas. Em três delas, respectivamente PUC, Unifesp e Unicamp, os membros optaram por demarcar, de início, o reconhecimento a ex-professores que se destacaram no enfrentamento, ou foram perseguidos pela ditadura, e atribuíram às comissões os nomes dos homenageados.

Assim, a Comissão da Verdade da Pontifícia Universidade Católica de São Paulo celebra a memória da professora Nadir Gouvêa Kfouri, reitora no período de 1976 a 1984, a primeira mulher a ocupar esse cargo no país e a primeira indicada pelo voto direto da comunidade acadêmica. Firme na condução da universidade, abriu as portas da PUC para intelectuais como Paulo Freire e Florestan Fernandes, perseguidos pelo regime militar. Manteve altivez e serenidade nos episódios de grande tensão na instituição, como a invasão da

\footnotetext{
É conhecida a prática de desaparecimento de militantes e ocultação de corpos durante o regime militar. Na cidade de São Paulo, alguns dos militantes desaparecidos foram localizados na vala clandestina de Perus, no Cemitério Dom Bosco, de onde, em 1990 foram exumadas mais de mil ossadas de presos políticos de pessoas consideradas indigentes, todos vítimas do Esquadrão da Morte (COMISSÃO DA VERDADE DO ESTADO DE SÃO PAULO RUBENS PAIVA, 2015). O caso, com grande repercussão na imprensa, é reportado no livro do jornalista Caco Barcellos (1997), Rota 66, que trata de suas investigações sobre o esquadrão da morte, e mais recentemente no livro Vala de Perus (VANNUCHI, 2020), iniciativa do Instituto Vladimir Herzog.
} 
Universidade por forças policiais em 1977. Segundo o relatório da Comissão, conta-se que neste acontecimento, Erasmo Dias, então Secretário de Segurança de São Paulo, exigiu que a reitora se identificasse. E ela respondeu: "a casa é minha. Identifique-se o senhor". Em seguida, recusou-se a cumprimentá-lo, dizendo: "não dou a mão a assassinos" (COMISSÃO DA VERDADE DA PUC-SP, 2017).

A Comissão da Unifesp rememora seu ex-reitor Marcos Lindenberg. Enquanto diretor da Escola Paulista de Medicina (EPM), foi um dos idealizadores da Universidade Federal de São Paulo, tendo assegurado abertura para participação estudantil nas instâncias decisórias da universidade, entre as quais o Conselho Universitário, órgão máximo de deliberação institucional. Em 1964, foi instaurado Inquérito Policial Militar (IPM) contra Lindenberg que resultou em sua exoneração do cargo de diretor da Escola Paulista. Em seguida, foi aposentado compulsoriamente de seu cargo como professor (BIONDI, 2008).

Por fim, a Comissão da Unicamp leva o nome de Octávio lanni. Sociólogo de formação, Ianni lecionou inicialmente na Universidade de São Paulo, onde foi aposentado pelo Ato Institucional número 5 (AI-5). Proibido de atuar na USP, Ianni ingressou na PUC, que recebeu diversos acadêmicos impedidos de lecionar em instituições públicas, entre os quais Florestan Fernandes, Paul Singer e Paulo Freire. Ianni lecionou também em universidades estrangeiras e em 1997 retornou para a USP, como professor emérito. Ali se indispôs com alguns colegas e voltou para sala de aula apenas na Universidade Estadual de Campinas, por onde também recebeu o título de professor Emérito.

Para além das denominações, os Relatórios destacaram em suas Recomendações os membros de suas comunidades que foram perseguidos, torturados ou submetidos a desaparecimento forçado. Uma das formas de rememoração foi a instituição de marcos territoriais, por meio de monumentos e memoriais, forma de assinalar as ações de repressão e as lutas de resistência, como recomendaram as Comissões da USP, PUC e Unifesp. No caso da PUC, o Monumento ao "Nunca Mais" foi inaugurado em 2 de abril de 2014, em ato organizado por sua Comissão da Verdade e com a presença da comunidade acadêmica, familiares de mortos e desaparecidos, membros do governo federal 
e municipal e representantes das Comissões Estadual e Nacional e de entidades ligadas à defesa dos direitos humanos (COMISSÃO DA VERDADE DA PUC-SP, 2017).

A USP, por sua vez, havia criado em 2011 o Memorial aos Membros da Comunidade USP Vítimas do Regime da Ditadura Militar (1964-1985), por iniciativa do Núcleo de Estudos da Violência, instalado na Praça do Relógio, ponto central da Cidade Universitária, na proximidade da Reitoria e Museus. No Memorial estão relacionados membros da comunidade que desapareceram ou morreram pela ação da ditadura militar, porém a Comissão da Verdade da USP recomendou a inclusão de nove outros nomes levantados ${ }^{11}$. Em 2018, o Memorial foi objeto de reportagem relatando sua deterioração, inclusive com pichações (CRISTINA, 2018).

O documento da Unifesp ${ }^{12}$ não indica locais de recordação e preservação da memória, mas observa que caso sejam criados o processo seja amparado por editais e concursos organizados pelo departamento de História da Arte com participação do corpo discente da graduação. A Comissão recomenda, ainda, que se rememorem membros da comunidade acadêmica que sofreram violações aos direitos humanos por meio da demarcação de locais com seus nomes em bibliotecas, auditórios, institutos, laboratórios e demais locais de intensa atividade acadêmica.

Além de marcos territoriais, a Comissão da USP (2015) recomenda a diplomação dos discentes mortos ou desaparecidos pela ação da ditadura. Há situações específicas de efeitos institucionais que se alongaram no tempo, como o da professora Lúcia Maria Sálvia Coelho, da Faculdade de Medicina. Depois de presa pelo regime militar, sua contratação não foi formalizada quando retomou a docência, embora seguisse trabalhando. No Relatório, a Comissão indica a necessidade de reparação aos danos causados.

\footnotetext{
11 São eles: Alexander José Ibsen Voerões, Boanerges de Souza Massa, Henrique Cintra Ferreira de Ornellas, Jane Vanini, Juan Antonio Carrasco Forrastal, Maria Regina Marcondes Pinto, Miguel Pereira dos Santos, Sergio Roberto Correa e Wânio José de Matos.

12 Disponível em https://www.unifesp.br/images/DCl/Recomendacoes_CONSU_CVML.
} 


\section{As Recomendações e suas consequências}

Ainda em relação à USP, duas recomendações foram atendidas pela Reitoria na gestão de Marco Antonio Zago: a primeira relacionada a Ana Rosa Kucinski e a segunda ao professor Hélio Lourenço de Oliveira.

Ana Rosa Kucinski trabalhava como assistente no Departamento de Química Fundamental da USP, e desapareceu em 22 de abril de 1974, após ser presa pelo Estado brasileiro. Seu desaparecimento foi denunciado pela família inclusive internacionalmente, e o Estado brasileiro seguiu negando sua prisão. Assim, Kucinski foi demitida por abandono de função, sendo ignoradas as circunstâncias de seu desaparecimento, e reforçando uma narrativa de que esta não se encontrava em responsabilidade do Estado (UNIVERSIDADE DE SÃO PAULO, 2015). Em 2012, movimentos de direitos humanos requereram a revogação de tal decisão, pedido que sofreu resistências: os argumentos iam da impossibilidade jurídica de revogação à necessidade de respeito da decisão da congregação à época (ALMEIDA, 2017). A Comissão da Verdade da USP, criada em 2013, fez no ano seguinte à sua criação a solicitação de anulação da demissão de Kucinski à Congregação do Instituto de Química, que respondeu com decisão favorável. Assim, a demissão por abandono de função foi considerada um equívoco e dois atos marcaram esta revisão: um pedido formal de desculpas à família de Ana Rosa, por parte da Congregação, e a inauguração de monumento em sua homenagem no instituto, em 22 de abril de 2014, 40 anos depois de seu desaparecimento (ALMEIDA, 2017; UNIVERSIDADE DE SÃO PAULO, 2015).

A reparação para o professor Hélio Lourenço Oliveira, cassado pelo Al-5 enquanto exercia a função de reitor, se deu por meio de homenagem pública em 2017 que reconduziu seu quadro na galeria dos reitores da instituição (UNIVERSIDADE DE SÃO PAULO, 2015).

Um conjunto razoável de recomendações comparece nos diferentes relatórios. A mais frequente indica a continuidade da coleta de informações, análise de dados, prosseguimento na tomada de depoimentos. A ênfase na organização de acervo físico e digital, sempre que possível, também é recorrente. Em sintonia com a Comissão Nacional da Verdade, as Comissões analisadas, exceto a FESPSP, recomendam a inclusão de conteúdos voltados para a história 
recente do Brasil, incentivando valores democráticos, direitos humanos e diversidade cultural nos currículos escolares. As Comissões da USP, PUC e Unifesp recomendam ainda estímulo à produção de pesquisas voltadas para Justiça de Transição e os debates sobre a Lei da Anistia.

Outra recomendação conjunta das três Comissões é a criação do Observatório em Defesa dos Direitos Humanos voltado para apurar casos de violações em relação a estudantes, professores e demais servidores das instituições universitárias. Uma iniciativa que se aproxima dessa recomendação é conduzida pelo Núcleo de Estudos da Violência (NEV-USP) que administra o Projeto Observatório de Direitos Humanos nas Escolas (PODHE, c2021).

Na Unifesp a criação do Observatório da Proteção dos Direitos Humanos se deu em 2019, como projeto de extensão do Centro de Antropologia e Arqueologia Forense e foi, no mesmo ano, credenciado pela instituição em sua Política de Observatórios. Desde então, atua em duas linhas temáticas: Proteção dos espaços de ativismo por Direitos Humanos e Promoção dos Direitos Humanos e Preservação da Memória de Graves Violações. Por meio da segunda Linha, o Observatório atua no âmbito da Rede Monitora CNV, criada com o objetivo de acompanhar a implementação das recomendações estabelecidas pela Comissão Nacional, em parceria com o Instituto Vladimir Herzog e o Núcleo de Direitos Humanos da PUC/RJ (CALAZANS, 2020). ${ }^{13}$

Em 2018, a Unicamp criou o Observatório de Direitos Humanos, como iniciativa do corpo acadêmico (OBSERVATÓRIO, 2019?). Embora o Relatório Final não tenha explicitado essa recomendação, a iniciativa pode ser entendida como decorrência do ambiente favorável deflagrado pelo intenso debate e comoção que acompanharam a instalação e o funcionamento de sua Comissão da Verdade.

Um aspecto comum nas recomendações da USP e Unicamp aponta para a revisão, não realizada, dos Regimentos Internos que mantêm resquícios de

\footnotetext{
13 A PUC mantém desde 2005 o Observatório das Violências Policiais, integrado ao Centro de Estudos de História da América Latina (CEHAL). Em 2017 tornou-se Observatório de Violências Policiais e dos Direitos Humanos. Porém, não há registro de que essa alteração tenha se vinculado às recomendações da Comissão da Verdade (OVP-SP, 2012).
} 
autoritarismo. O Relatório da Unicamp (ARAÚJO, et al., 2015) indica especificamente a necessidade de modificação dos artigos 227, 234 e 235 que tratam do regime disciplinar. O Artigo 227, por exemplo, trata de infrações disciplinares e estabelece como simétricas questões muito distintas como evidencia o texto do Regimento transcrito a seguir: "VIII. Praticar manifestações, propaganda ou ato de caráter político-partidário ou ideológico, de discriminação religiosa ou racial, de incitamento ou de apoio à ausência aos trabalhos escolares" (SÃO PAULO, 2011)14. No caso da USP, o Regime Disciplinar está regulamentado pelo Regimento Geral instituído em 1972. Em razão dessa defasagem, a Comissão (USP, 2015) recomenda a alteração do artigo 247 que considera infração "VIII promover manifestação ou propaganda de caráter político-partidário, racial ou religioso, bem como incitar, promover ou apoiar ausências coletivas aos trabalhos escolares" (SÃO PAULO, 1972).

No Relatório da Unicamp (ARAÚJO, et al., 2015), é muito citada a figura de seu primeiro reitor Zeferino Vaz que permaneceu no cargo por doze anos, desde sua criação em 1965, até 1977, período no qual manteve vínculos muito estreitos com a ditadura civil-militar. Parte dos relatos colhidos considera que Zeferino soube usar dessa proximidade para reduzir interferências do regime na Unicamp. Por outro lado, tal proximidade levou para o campus símbolos da própria ditadura, elementos sobre os quais a Comissão recomenda esclarecimentos. Uma dessas solicitações questiona o Painel da Praça das Bandeiras, instalado no campus, onde consta como "Senhor Presidente da República" a figura de Marechal Castelo Branco, lembrando que o militar exerceu esse cargo com mandato decretado pela ditadura (ARAÚJO, et al., 2015).

O reconhecimento de responsabilidade jurídica dos agentes públicos aparece igualmente como recomendação nos relatórios. Por fim, a Comissão da Universidade de São Paulo (2015) indica que se encaminhe informações sobre os ilícitos penais, administrativos ou civis ao Ministério Público, reforçando desse modo a defesa das instituições democráticas e do Estado de Direito.

\footnotetext{
${ }^{14}$ Apesar de haver alterações no Regimento, sendo o de 2019 o mais atualizado, esta alínea se mantém no Art. 220, do Capítulo II. Da Representação Estudantil.
} 


\section{Caso Jarbas Passarinho}

Ministro da Educação entre 1969 e 1974, o coronel do Exército Jarbas Passarinho recebeu o título de Doutor Honoris Causa por duas instituições de São Paulo, FESPSP e Unicamp, e os Relatórios de ambas recomendaram a revogação do título. No caso da Unicamp, a questão suscitou tensões e conflitos. O Conselho Universitário (Consu), reunido em 5 de agosto de $2014^{15}$, antes da publicação deste relatório, decidiu pela manutenção do título. O tema entrou na pauta a partir da moção de quatro Faculdades e Institutos da própria Unicamp, com o apoio de sua própria Comissão da Verdade e de outras sete (UnB, UFRJ, Unesp, UFES, Unifesp, UFPR, PUC-SP). Para a revogação seriam necessários 50 votos favoráveis, equivalentes a dois terços do Conselho. O título foi mantido, porém, por uma margem muito reduzida: 49 votos favoráveis, 10 contrários e 10 abstenções.

As tensões contidas no enfrentamento das memórias estiveram no centro do debate. Os defensores da revogação assinalaram a inconveniência de assegurar um título honroso para um personagem que expressou a face mais violenta e autoritária do regime. Os conselheiros contrários argumentaram que não se deveria modificar uma decisão do passado. Alegaram constrangimento de reverter a decisão de conselheiros precedentes, deslegitimando a autoridade do próprio Conselho. Defensores da revogação, por sua vez, assinalaram que manter o título significaria reafirmar a homenagem.

No caso da FESPSP, não foram encontradas informações públicas acerca do caso, não constando indicativos que se tenha revogado tal título.

\section{Considerações finais}

A experiência das Comissões da Verdade demarcou a importância da memória como possibilidade de revisitação da história ao assegurar que vozes silenciadas pela violência, medo e censura, pudessem ser ouvidas perante uma narrativa oficial e naturalizada. A instituição da Comissão Nacional da Verdade (CNV) em 2011 permitiu que se avançasse no direito à memória e à verdade com

\footnotetext{
${ }^{15}$ Disponível em

https://www.sg.unicamp.br/content/uploads/sessoes/pautas/p2014/consu/138/ata-137.pdf.
} 
a premissa de garantia dos direitos humanos. O funcionamento da CNV, por sua vez, emulou a criação de comissões estaduais, municipais e temáticas - como as universitárias -, movimento que pode ser considerado como "excepcionalidade virtuosa" em razão da intensa mobilização social em busca de verdade e reparação.

Mais especificamente, o esforço de levantamento de arquivos, depoimentos e coleta de informações em torno do qual se articularam as Comissões Universitárias, assim como os debates contundentes que se impuseram intra e extramuros, restituíram para essas instituições parte do protagonismo político que havia esmaecido nas décadas anteriores. Esmaecimento que pode ser analisado como resultado do silenciamento de suas lideranças pela repressão, mas também pela avalanche da lógica produtivista que solapou em seguida a vida universitária, se acentuando ao longo dos anos 1990 e décadas subsequentes.

O contexto de "excepcionalidade virtuosa", como assinalado acima, evidenciou uma vez mais o caráter sensível dessas instituições como espaços privilegiados da crítica, mas expôs também os conflitos decorrentes da atuação de forças internas contrárias ao exercício da política como dimensão da construção do conhecimento. Se a oposição sistemática ao arbítrio do regime civil-militar de 1964 desencadeou pesadamente a ação repressiva colocando-a como um dos alvos principais, igualmente no contexto atual os ataques têm sido persistentes e notórios. Sob tal perspectiva, a luta pela memória, e em particular as Comissões da Verdade Universitárias, assume relevância ainda maior como possibilidade de desvendamento das forças contrárias ao exercício da crítica em sua plenitude.

Afinal, como evidenciaram os relatórios analisados, a acirrada disputa pela memória do período ficou evidente na proposta de revogação do título concedido a Jarbas Passarinho. No contexto daquela discussão, outros personagens reapareceram como a figura de Zeferino Vaz, que dirigiu a Unicamp entre 1965 e 1977, fase mais aguda da ditadura. A proximidade de Zeferino Vaz com o regime militar foi invocada como garantia de que a instituição se mantinha relativamente segura de interferências da ditadura. 
Neste sentido, para alguns conselheiros, revogar o título de Jarbas Passarinho seria indicar que o ex-reitor e o corpo de conselheiros do período cometeram um erro ao aprovar a homenagem, ato que poderia ter sido uma decisão estratégica na proteção da universidade. Os conselheiros contrários, por sua vez, reafirmaram tratar-se de homenagem descabida, uma vez que Jarbas Passarinho não contribuiu para educação pública. Afinal, não é excessivo lembrar que o ex-ministro foi responsável pela formulação do Decreto-Lei 477, de 1969, que punia professores, estudantes e servidores acusados de subversão pelo regime. O decreto amparou exonerações, expulsões e punições a um grande contingente de membros da comunidade universitária em todo o país e só foi revogado em 1979 como advento da Lei da Anistia.

Por fim, os relatórios permitem dimensionar o caráter, volume e intensidade das violações nas instituições universitárias. Múltiplas e persistentes no período de recrudescimento da repressão, as invasões, mortes e desaparecimentos, exclusão e interdição de contratos de trabalho a servidores e docentes, expulsão de discentes, controle e censura do ensino e pesquisa são eventos que continuam a merecer a devida análise e aprofundamento. Sobretudo na perspectiva de compreender as forças internas que atuaram e atuam em favor do arbítrio - talvez para se descobrir que tais presenças vão além de resquícios evidentes, por exemplo, em regimentos nos quais sobreviveram dispositivos disciplinares provenientes do período militar. Consideramos, portanto, que analisar, compreender e manter viva a memória das arbitrariedades do período são instrumentos fundamentais para assegurar que não se repitam.

\section{Referências}

ABRÃO, Paulo; TORELLY, Marcelo D. Justiça de transição no Brasil: a dimensão da reparação. In: SANTOS, Boaventura de Sousa et. al. (orgs.). Repressão e memória política no contexto ibero-brasileiro: estudos sobre Brasil, Guatemala, Moçambique, Peru e Portugal. Brasília: Ministério da Justiça, Comissão de Anistia; Coimbra: Universidade de Coimbra, Centro de Estudos Sociais, 2010. p. 24-57. Disponível em: https://www.justica.gov.br/central-deconteudo/anistia/anexos/repressao-e-memoria-no-contexto-iberoamenricano.pdf. Acesso em: 04 jun. 2020. 
ALMEIDA, Juan de Assis. Memória, universidade, cidadania e constituição na era das comissões da verdade: elucubrações comparativas a partir da vida e obra da família Kucinski. In: SIMPÓSIO NACIONAL DE HISTÓRIA, 19, 2017, Brasília. Anais [...]. Brasília: [s.n.], 2017. Tema: Contra os preconceitos: história e democracia. Disponível em:

https://www.snh2017.anpuh.org/resources/anais/54/1489624814_ARQUIVO_STA NPUH2017.pdf. Acesso em: 03 jun. 2020.

ANSARA, Soraia. Políticas de Memória X Políticas do Esquecimento: possibilidades de desconstrução da matriz colonial. Psicologia Política. São Paulo, v.12, n.24, 2012. p. 297-311. Disponível em:

http://pepsic.bvsalud.org/scielo.php?script=sci_arttext\&pid=S1519549X2012000200008. Acesso em: 04 jun. 2020.

ARAÚJO, Ângela Maria Carneiro; TOLEDO, Caio Navarro de; TEGA, Danielle; LIMA, Eduardo Garcia de; COVOLAN, Fernanda Cristina; MORAES, Maria Lygia Quartim de; CANO, Wilson (orgs.). Relatório final da comissão da verdade e memória “Octávio Ianni” da Unicamp. Campinas: UNICAMP, Gabinete do Reitor, 2015. Disponível em: https://www.comissaoverdade.gr.unicamp.br/pdf/RELATORIO_CVM_FINAL_web. pdf. Acesso em: 06 out. 2020.

BARCELLOS, Caco. Rota 66: A história da polícia que mata. São Paulo: Globo, 1997.

BIONDI, Luigi. "Não éramos mais universidade”: a política na Escola Paulista de Medicina, da universidade federal à ditadura. In: RODRIGUES, Jaime (org.); NEMI, Ana Lúcia Lana; LISBOA, Karen Macknow; BIONDI, Luigi. A Universidade Federal de São Paulo aos 75 Anos: ensaios sobre história e memória [online]. São Paulo: Unifesp, 2008. p. 141-185. Disponível em:

http://books.scielo.org/id/hnbsg/pdf/nemi-9788561673833-08.pdf. Acesso em: 04 jun. 2020.

BRAGATTO, Fernanda; PAULA, Luciana Araujo de. A memória como direito humano. In: RELATÓRIO AZUL 2011. [S.l.: s.n.], 2011. p.129-141. Disponível em: https://halshs.archives-ouvertes.fr/halshs-00920611/document. Acesso em: 11 set. 2020.

BRASIL. Constituição (1988). Constituição da República Federativa do Brasil. Brasília, DF: Senado Federal, 1988.

BRASIL. Comissão Nacional da Verdade. Relatório da comissão nacional da verdade. v.1. Brasília: CNV, 2014. 914p. Disponível em: http://cnv.memoriasreveladas.gov.br/images/pdf/relatorio/volume_1_digital.pdf. Acesso em: 04 jun. 2020. 
CALAZANS, Marília Oliveira. Observatório da Proteção dos Direitos Humanos. Unifesp. CAAF - Centro de Antropologia e Arqueologia Forense. 2020. Disponível em: https://www.unifesp.br/reitoria/caaf/projetos/observatorio-da-protecaodos-direitos-humanos. Acesso em: 04 jun. 2020.

\section{COMISSÃO DA VERDADE DA FUNDAÇÃO ESCOLA DE SOCIOLOGIA E POLÍTICA} DE SÃO PAULO. Relatório de Pesquisa. São Paulo, 2014.

COMISSÃO DA VERDADE DA PUC-SP. Reitora Nadir Gouvêa Kfouri. [S.l.: s.n., 2017]. Disponível em: https://www.pucsp.br/comissaodaverdade/sobre-acvpuc-apresentacao.html. Acesso em: 04 jun. 2020.

COMISSÃO DA VERDADE DO ESTADO DE SÃO PAULO RUBENS PAIVA. Relatório: Tomo I: Parte I: métodos e técnicas de ocultação de corpos na Cidade de São Paulo. [São Paulo: s.n.], 2015. Disponível em: http://comissaodaverdade.al.sp.gov.br/relatorio/tomoi/downloads/I_Tomo_Parte_1_Metodos-e-tecnicas-de-ocultacao-de-corpos-nacidade-de-Sao-Paulo.pdf. Acesso em: 16 set. 2020.

CORTE INTERAMERICANA DE DIREITOS HUMANOS. Caso Gomes Lund e outros ("Guerrilha do Araguaia") vs. Brasil. Sentença de 24 de Novembro de 2010. [S.l.: s.n.], 2010. Disponível em:

http://www.corteidh.or.cr/docs/casos/articulos/seriec_219_por.pdf. Acesso em: 08 jun. 2020.

CRISTINA, Ana. Memorial relembra membros da USP vítimas da ditadura militar. Jornal da USP, São Paulo, 2018. Disponível em: https://jornal.usp.br/?p=141281. Acesso em: 04 jun. 2020.

FAGUNDES, Pedro Ernesto. Comissão da Verdade na Universidade: um relato sobre o Caso da Comissão da Verdade da Universidade Federal do Espírito Santo (CVUfes). Revista Ágora, Vitória, n. 27, 2018. p. 121-131. Disponível em: https://periodicos.ufes.br/agora/article/view/19868. Acesso em: 04 jun. 2020.

GENRO, Tarso; ABRÃO, Paulo. Memória Histórica, Justiça de Transição e Democracia sem Fim. In: SANTOS, Boaventura de Sousa et. al. (orgs). Repressão e memória política no contexto ibero-brasileiro: estudos sobre Brasil, Guatemala, Moçambique, Peru e Portugal. Brasília: Ministério da Justiça, Comissão de Anistia; Portugal: Universidade de Coimbra, Centro de Estudos Sociais, 2010. p. 14-23. Disponível em: https://www.justica.gov.br/central-deconteudo/anistia/anexos/repressao-e-memoria-no-contexto-iberoamenricano.pdf. Acesso em: 04 jun. 2020. 
MOTTA, Rodrigo Patto Sá. Os olhos do regime militar brasileiro nos campi. As assessorias de segurança e informações das universidades. Topoi, Rio de Janeiro, v. 9, n. 16, 2008, p. 30-67. Disponível em: https://www.scielo.br/scielo.php?pid=S2237-

101X2008000100030\&script=sci_arttext\&tlng=pt. Acesso em: 04 jun. 2020.

MÜLLER, Angélica; FAGUNDES, Pedro Ernesto. O trabalho das comissões da verdade universitárias: rastreando vestígios da repressão nos campi durante a ditadura militar. Ciência e Cultura, São Paulo, v.66, n.4, 2014. p. 44-47. Disponível em: http://cienciaecultura.bvs.br/scielo.php?script=sci_arttext\&pid=S000967252014000400014\&lng=en\&nrm=iso. Acesso em: 04 jun. 2020.

\section{OBSERVATÓRIO de Direitos Humanos. Universidade Estadual de Campinas:}

Diretoria Executiva de Direitos Humanos. [Campinas: s.n., 2019?]. Disponível em: http://www.direitoshumanos.unicamp.br/observatorio-de-direitos-humanos-0. Acesso em: 04 jun. 2020.

OLIVEIRA, Sonale Diane Pastro de; MARINHO, Maria Gabriela da Silva Martins da Cunha. A internet, um novo espaço de disputa pela memória da ditadura militar no Brasil. Revista Tempo e Argumento, Florianópolis, v. 5, n.10, 2013. p. 159-181. Disponível em:

http://www.revistas.udesc.br/index.php/tempo/article/view/217518030510201315 9. Acesso em: 04 jun. 2020.

OLIVER, Miguel Gómez. El Movimiento Estudiantil español durante el Franquismo (1965-1975). Revista Crítica de Ciências Sociais, Coimbra, n.81, 2008. p. 93-110 Disponível em: http://journals.openedition.org/rccs/652. Acesso em: 04 jun. 2020.

OVP-SP. Apresentação: A trajetória do OVP-SP. Observatório das Violências Policiais - SP. 2012. Disponível em: http://www.ovp-sp.org/apresentacao1.htm. Acesso em: 04 jun. 2020.

PODHE. NEV - Núcleo de Estudos da Violência da Universidade de São Paulo. [São Paulo: s.n., c2021]. Disponível em: https://nev.prp.usp.br/projetos/projetosespeciais/podhe/. Acesso em: 04 jun. 2020.

POLLACK, Michael. Memória, esquecimento, silêncio. Estudos Históricos, Rio de Janeiro, v. 2, n. 3, 1989. p. 3-15. Disponível em:

http://www.uel.br/cch/cdph/arqtxt/Memoria_esquecimento_silencio.pdf. Acesso em: 04 jun. 2020. 
QUIJANO, Aníbal. Colonialidade do poder, eurocentrismo e América Latina. In: LANDER, Edgardo. A colonialidade do saber: eurocentrismo e ciências sociais: perspectivas latino-americanas. Buenos Aires: CLACSO, Consejo Latinoamericano de Ciencias Sociales, 2005. p. 117-140. Disponível em: http://biblioteca.clacso.edu.ar/clacso/sur-sur/20100624103322/12_Quijano.pdf. Acesso em: 04 jun. 2020.

SANTOS, Cecília Macdowell. Memória na justiça: a mobilização dos direitos humanos e a construção da memória da ditadura no Brasil. Revista Crítica de Ciências Sociais, Coimbra, n.88, 2010. p. 127-154. Disponível em: https://journals.openedition.org/rccs/1719. Acesso em: 04 jun. 2020.

SÃO PAULO (Estado). Decreto no 52.906, de 27 de março de 1972. Aprova o Regimento Geral da Universidade de São Paulo. Diário Oficial - Executivo, São Paulo: Assembléia Legislativa do Estado de São Paulo, 1972. Disponível em: https://www.al.sp.gov.br/repositorio/legislacao/decreto/1972/decreto-5290627.03.1972.html. Acesso em: 04 jun. 2020.

SÃO PAULO (Estado). Regimento Geral da Universidade Estadual de Campinas. Campinas: Unicamp, 2011. Disponível em: https://www.sg.unicamp.br/download/documentos/91c5519c0f2f682dfb4ec575e Obafa7c. Acesso em: 04 jun. 2020.

SEIA, Guadalupe A. Militancia, oposición y resistencia estudiantil en la Universidad de Buenos Aires durante la etapa final de la última dictadura (19811983). Historia, Voces y Memoria, n.10, 2016. p. 21-34. Disponível em: http://revistascientificas.filo.uba.ar/index.php/HVM/article/view/3379. Acesso em: 04 jun. 2020.

SILVA FILHO, José Carlos Moreira da. Dever de memória e a construção da história viva: a atuação da Comissão de Anistia do Brasil na concretização do direito à memória e à verdade. In: SANTOS, Boaventura de Sousa et. al. (orgs). Repressão e memória política no contexto ibero-brasileiro: estudos sobre Brasil, Guatemala, Moçambique, Peru e Portugal. Brasília: Ministério da Justiça, Comissão de Anistia; Portugal: Universidade de Coimbra, Centro de Estudos Sociais, 2010. p. 184-225. Disponível em: https://www.justica.gov.br/central-deconteudo/anistia/anexos/repressao-e-memoria-no-contexto-iberoamenricano.pdf. Acesso em: 04 jun. 2020.

TORELLY, Marcelo. Justiça transicional, memória social e senso comum democrático: notas conceituais e contextualização do caso brasileiro. In: SANTOS, Boaventura de Sousa et. al. (orgs). Repressão e memória política no contexto ibero-brasileiro: estudos sobre Brasil, Guatemala, Moçambique, Peru e Portugal. Brasília: Ministério da Justiça, Comissão de Anistia; Portugal: Universidade de Coimbra, Centro de Estudos Sociais, 2010. p. 102-121. Disponível em: https://www.justica.gov.br/central-de-conteudo/anistia/anexos/repressaoe-memoria-no-contexto-ibero-amenricano.pdf. Acesso em: 04 jun. 2020. 
UNIVERSIDADE DE SÃO PAULO [USP]. Comissão da Verdade da Universidade de São Paulo. Relatório final. São Paulo: Universidade de São Paulo, 2015. 11 vols. Disponível em: http://sites.usp.br/comissaodaverdade/relatorio-final/. Acesso em: 06 out. 2020.

UNIVERSIDADE FEDERAL DE SÃO PAULO [UNIFESP]. Comissão da Verdade Marcos Lindenberg da Unifesp. Informe sobre o Relatório da Comissão da Verdade Marcos Lindenberg da Unifesp. São Paulo: Unifesp, 2016. Disponível em: https://www.unifesp.br/images/DCl/Informe_relatorio_CVML. Acesso em: 06 out. 2020.

VANNUCHI, Camilo. Vala de Perus: uma biografia. [S.L.]: Portal Memórias da Ditadura, 2020. Disponível em: http://memoriasdaditadura.org.br/vala-de-perusuma-biografia/. Acesso em: 10 out. 2020. 